\title{
Ossifying Fibromyxoid tumor of soft parts in head and neck: case report and literature review
}

Ignacio A. Velasco ${ }^{1 \dagger}$, Ran Zhang $^{2 \dagger}$, Tiejun $\mathrm{Li}^{2}$ and Diancan Wang ${ }^{1 *}$

\begin{abstract}
Background: Ossifying fibromyxoid tumor of soft parts (OFMT), is a rare but morphologically distinctive neoplasm of uncertain histogenesis that most frequently affects middle-aged male adults. Clinically, it usually presents as a slowly enlarging, small, circumscribed mass, which in most cases is painless. OFMT is most frequently found within the subcutaneous tissues of extremities or trunk, and rarely in the oral/head and neck region. We present an unusual case of this tumor in the submandibular region, and, based on the current medical literatures this is probably the first case described in this anatomical location.

Case presentation: A 32-year-old male presented to our outpatient clinic with a right submandibular mass with 1 -year of evolution. Excisional biopsy showed that it was characterized by ossification along the periphery of the lesion. The neoplastic cells were spindle-like with scant eosinophilic cytoplasm. These cells were arranged with uniform cell-to-cell space in a fibromyxoid stroma. Small and large clusters of calcifications were present within the tumor. Immunohistochemically, the case showed positive staining of S-100 protein, vimentin, nestin, calponin, SMA, GFAF, desmin, INI-1, caldesmon, and CD34. It also showed negative staining of CK, CK7, CK8/18, NF, and EMA. About $2 \%$ of neoplastic cells showed positive staining of Ki67. Based on these features, the final pathological diagnosis was OFMT.
\end{abstract}

Conclusions: It is hoped that a greater understanding of OFMT in the head and neck region will avoid potential misdiagnosis, and contribute to determining the correct management, which appears to be complete surgical excision with close follow-up for recurrence surveillance.

Keywords: Ossifying Fibromyxoid tumor, Head and neck Neoplasms

\section{Background}

Ossifying fibromyxoid tumor of soft parts (OFMT) was first described by Enzinger et al. in 1989, and is a rare but morphologically distinctive neoplasm of undetermined histogenesis [1]. OFMT most frequently affects middle-aged adults, with a slight male predominance [2]. Clinically, it usually presents as a slowly enlarging, small, circumscribed mass, which in most cases is painless, although it can infrequently cause symptoms such as pain and paresthesia [3]. OFMT is most frequently found within

\footnotetext{
* Correspondence: bjwdc@sina.com

${ }^{\dagger}$ Equal contributors

'Department of Oral and Maxillofacial Surgery, Peking University School and Hospital of Stomatology, 22 South Zhongguancun Avenue, Beijing 100081,

People's Republic of China

Full list of author information is available at the end of the article
}

the subcutaneous tissues of the extremities or trunk, and is rarely found in the oral/head and neck region [2-6].

OFMT is typically composed microscopically of lobules of small polygonal to spindle-shaped cells with vesicular nuclei, discernible nucleoli, and eosinophilic cytoplasm, arranged in cords, trabeculae, or clusters in a loose fibromyxoid matrix [3]. Although most OFMTs fit this histologic description and show consistently benign clinical behavior, a subgroup of OFMT displays atypical histopathologic features, such as high cellularity or increased mitotic activity, and show a more aggressive clinical behavior [3]. In the vast majority of cases, complete surgical excision is curative; however, recurrences and distant metastasis have been reported in cases that presented with high mitotic activity and cytologic atypia $[2,3,5]$. 
The objective of our study is to describe an unusual clinical presentation of this tumor in the submandibular region. Based on the current medical literatures, this is probably the first case described in this anatomical location. Additionally, a literature review was performed with particular emphasis on previously reported cases affecting the oral/head and neck region.

\section{Case presentation}

A 32-year-old Asian male patient presented to the outpatient clinic of Peking University Hospital of Stomatology (Beijing, China) with1-year history of a right neck mass; the patient's past medical history was noncontributory. Extraoral clinical examination revealed a soft and slightly movable mass in the right submandibular region with normal overlying skin (Fig. 1a); the remaining physical examination results were within normal limits. The patient underwent computed tomography $(\mathrm{CT})$, and the data were processed using the image viewer InVesalius 3.0.0 version (Centre for Information Technology Renato Archer, Campinas, SP, Brazil). CT imaging showed a large $\left(5 \times 3 \mathrm{~cm}^{2}\right)$ mixed lesion with defined margins that was adjunct to the right submandibular gland (Fig. 1b). Additional tissue masks were created using the image viewer and these revealed that the tumor was possibly composed of fat, connective, and osteoid tissues (Fig. $2 \mathrm{a}-\mathrm{c}$ ). The primary differential diagnoses considered for this lesion included pleomorphic adenoma of the submandibular gland, teratoma, and osteo/chondroid lipoma.

Excisional biopsy was performed through an extraoral approach with submandibular gland preservation (Fig. 2d). Gross specimen dissection revealed the presence of hard tissues in the mass (Fig. 2e) and intraoperative frozen sections tested negative for malignancy. The postoperative period was uneventful and there were no signs of recurrence in the first 6 months of follow-up.

\section{Material and methods}

The tissue sections were fixed in formalin, embedded in paraffin (the thickness is $5 \mu \mathrm{m}$ ) and then were stained with haematoxylin-eosin and immunohistochemistry. Following heat-induced epitope retrieval, slides were incubated with antibodies specific for: S-100, nestin, calponin, vimentin, cytokeratin(CK), cytokeratin 7 (CK7), CK8/18, calponin, smooth muscle actin (SMA), glialfibrillary acidic protein (GFAP), neurofilament (NF), desmin, caldesmon, CD34, epithelial membrane antigen (EMA) and INI-1 (Dako, Denmark; Zhongshanjinqiao, China). Detection of the immunoreactionwas performed using second antibodies and ZLI-9017/9018/9019 DAB kit (both from Zhongshanjinqiao, China).

The literature review was performed using the PubMed/ MEDLINE electronic database to identify relevant publications from January 1989 through to December 2016 using the following search terms: "ossifying fibromyxoid tumor AND head and neck neoplasms." From the publications obtained in this search, those pertaining to cases of OFMT in the oral/head and neck region were included in the review [1, 4-26]. Additionally, a manual search was conducted by cross-referencing the retrieved manuscripts. All available data were reviewed, including clinical presentation, histopathologic examination findings (cytologic aty$\mathrm{pia} /$ mitotic activity), and surgical intervention (Table 1).
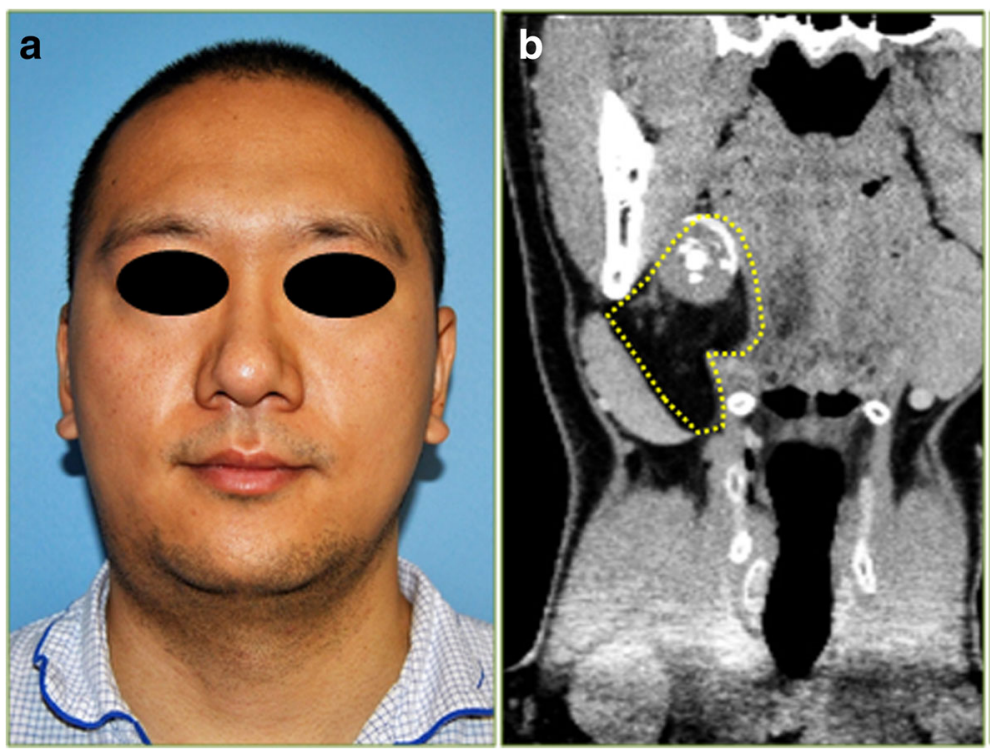

Fig. 1 Extraoral photograph shows a mass in the patient's right submandibular region (a). Coronal head CT scan shows a mixed lesion (outlined by the dotted line) near the right submandibular gland (b) 

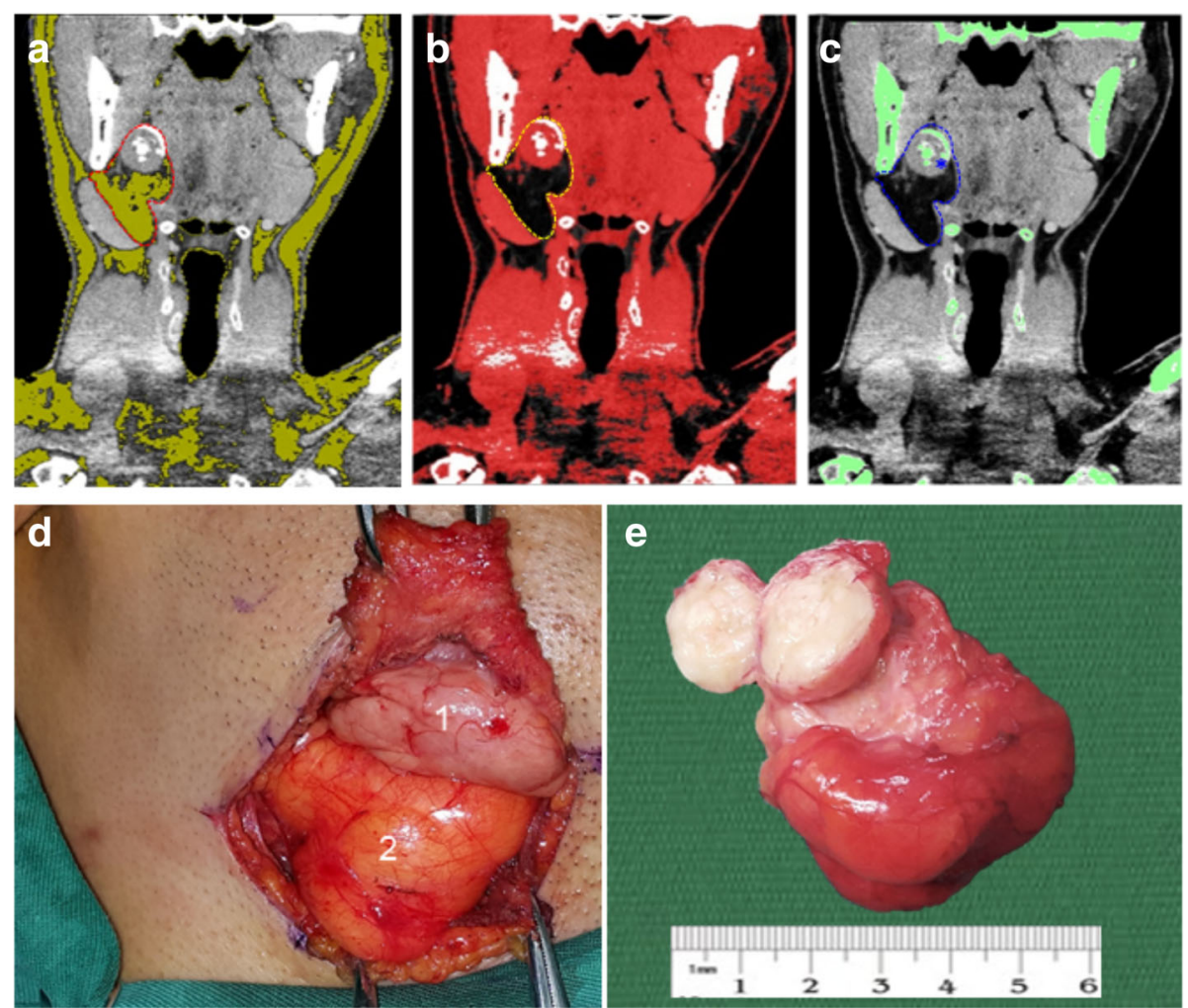

Fig. 2 Additional tissue masks were made using the image viewer revealing that the tumor waspossibly composed of fat (yellow) (a), connective tissues (red) (b), and osteoid materials (green) (c) as outlined by the dotted line. Intraoperative photograph shows submandibular gland (1), lesion (2) (d). Gross specimen of the lesion after the surgery (e).

\section{Results}

\section{Case presentation}

Examination of the biopsy specimen showed a $5.5 \mathrm{~cm} \times$ $5 \mathrm{~cm} \times 3 \mathrm{~cm}$, rubbery, fragile, gray-white colored, welldefined tumor that was surrounded by dark yellow lobulated soft tissues (Fig. 3a). Histologically, ossification was present along the periphery of the lesion (Fig. $3 \mathrm{~b}-\mathrm{c}$ ). The neoplastic cells were separated by fibrous septa and arranged in nests and cords (Fig. 3d). Neoplastic cells were spindle-like with scant eosinophilic cytoplasm. These cells were arranged with uniform cell-to-cell space in a fibromyxoid stroma (Fig. 3e). Small and large clusters of calcifications were present within the tumor (Fig. 3f). The neoplasm was closely associated with the glands, which were composed of dominant mucous components and suspected to be sublingual glands or minor salivary glands. Outside of the neoplasm, nodules of neoplastic cells had invaded into the adjacent tissues (Fig. 3g). Small clusters of lesion cells were found in the adjacent soft tissues (Fig. 3h and i). Immunohistochemically, the case showed positive staining of S-100 protein, vimentin, nestin, INI-1, calponin, SMA, GFAP, desmin, caldesmon, and CD34. It also showed negative staining of CK, CK7, CK8/18, NF, and EMA (Fig. 4a-c, h). About $2 \%$ of neoplastic cells showed positive staining of Ki67
(Fig. 4d). Small lesions in the adjacent soft tissues showed similar immunohistochemical staining patterns in immunohistochemistry (Fig. 4e-g). Based on these features, the final pathological diagnosis was OFMT.

\section{Literature review}

Twenty-eight articles with well-documented OFMT cases affecting the oral/head and neck region were reviewed; all articles were published between 1989 and December 2016. Table 1 describes the epidemiology, clinical presentation, surgical treatment, and outcome of this sample population, in addition to one new case that was reported $(n=88)$. According to the data reviewed, OFMT in the head and neck region usually presents as a painless subcutaneous mass in middle-aged men. OFMT in the oral cavity was seen in 8 of 88 cases $(9 \%)$ and a less common location was the nasal cavity $(4 / 88,5 \%)$, where it was associated with pain and nasal congestion. The preferred surgical treatment in the majority of cases was local excision; however, more radical excisions were performed in recurrent disease. Increased mitotic activity of $>2$ per 10 high-power fields (HPFs) and cytological atypia was seen in 12/45 (27\%) and 8/68 (12\%) cases, respectively. At least 1 episode of recurrence was described in 15 of 70 cases (21\%) and was associated in 


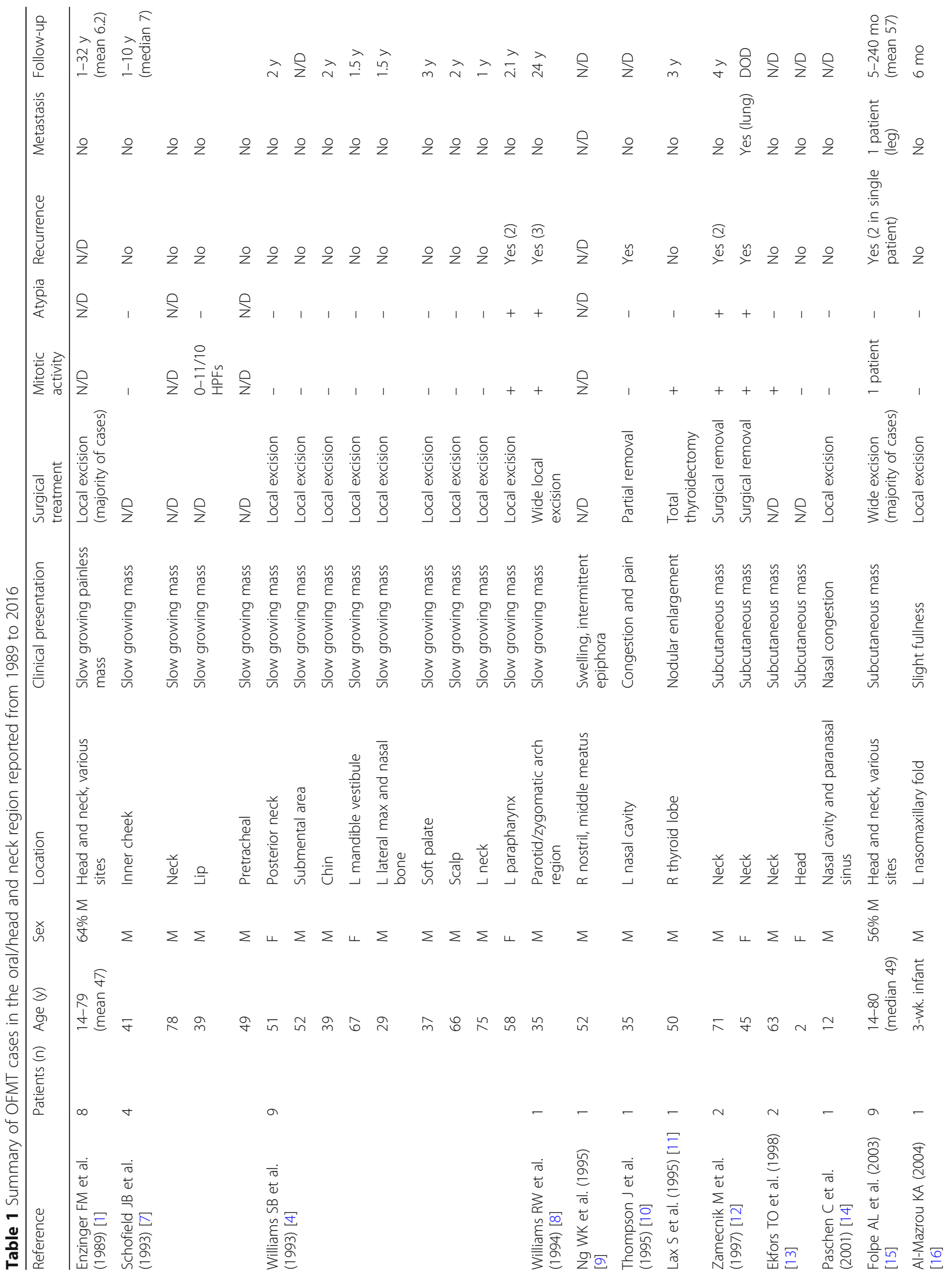




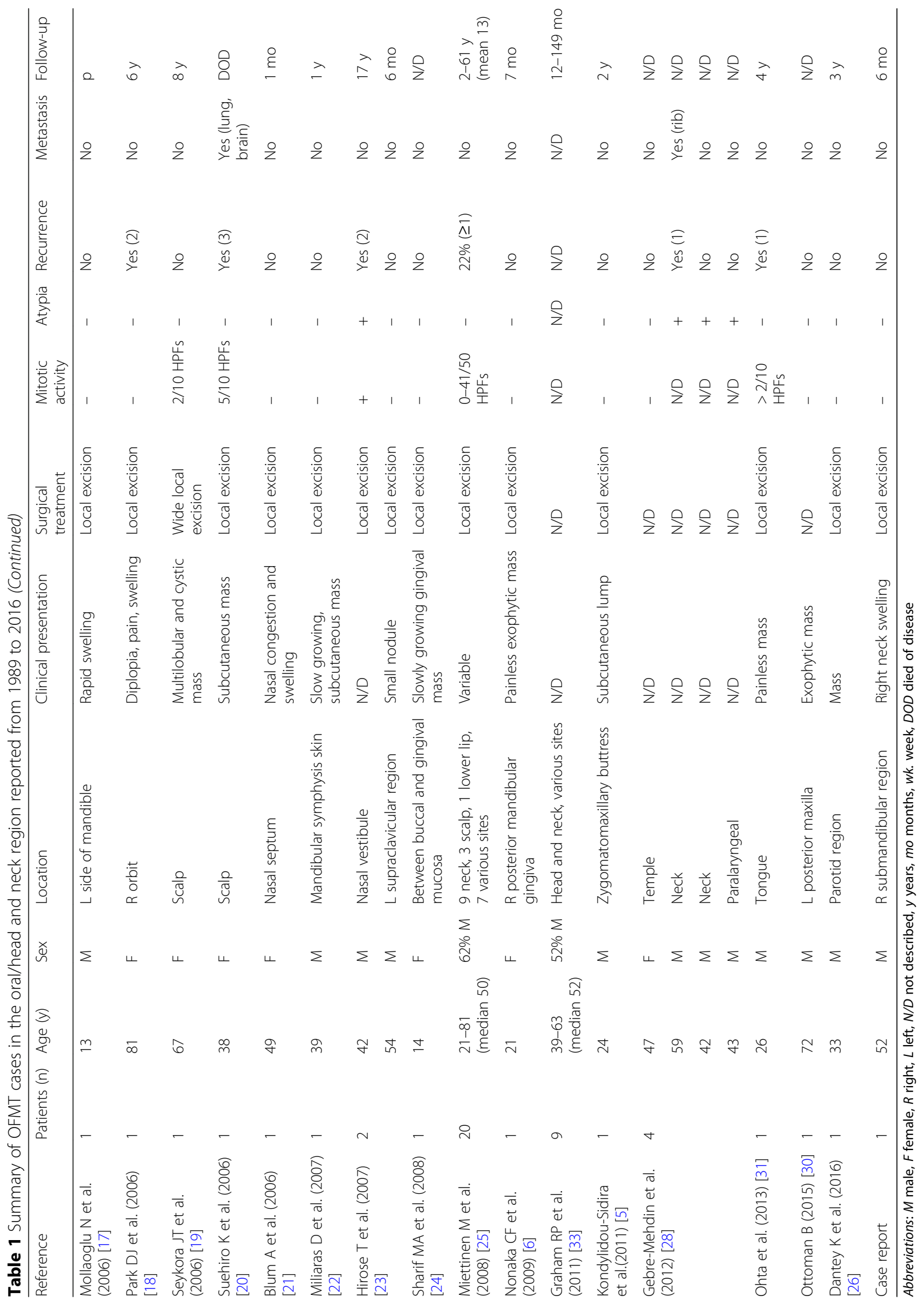



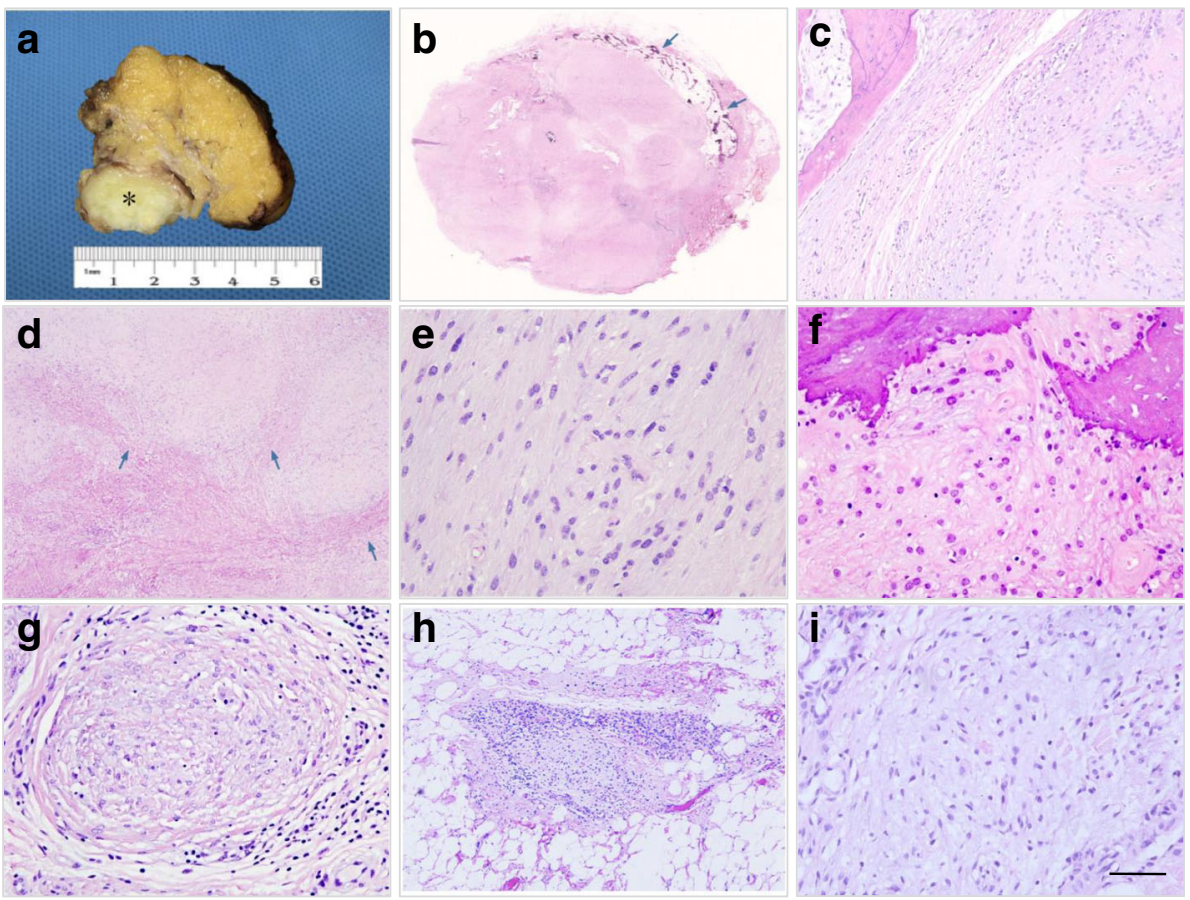

Fig. 3 Ossifying fibromyxoid tumor. The cut surface of the tumor is oval, gray-white and well-demarcated from the adjacent soft tissues with delicate fibrous septa (asterisk indicates) (a). The tumor is associated with a peripheral shell of metaplastic bone (arrows indicate) (b, c). Fibrous septa can be seen from the capsule into the neoplasm, separating them into cellular islands (d). Cells in this case are typically uniform, they are polygonal or spindle shape with fibromyxoid-appearing matrix (e). Clusters of calcification are within the tumor (f). Nodules of tumor cells can be seen outside of the capsule $(\mathbf{g})$. Sections of the soft tissues adjacent to the tumor show clusters of tumor cells $(\mathbf{h}, \mathbf{j})$. Scale bar: $250 \mu \mathrm{m}(\mathbf{d})$, $100 \mu \mathrm{m}(\mathbf{h}), 50 \mu \mathrm{m}(\mathbf{c}), 25 \mu \mathrm{m}(\mathrm{e}, \mathrm{f}, \mathrm{g}, \mathrm{i})$

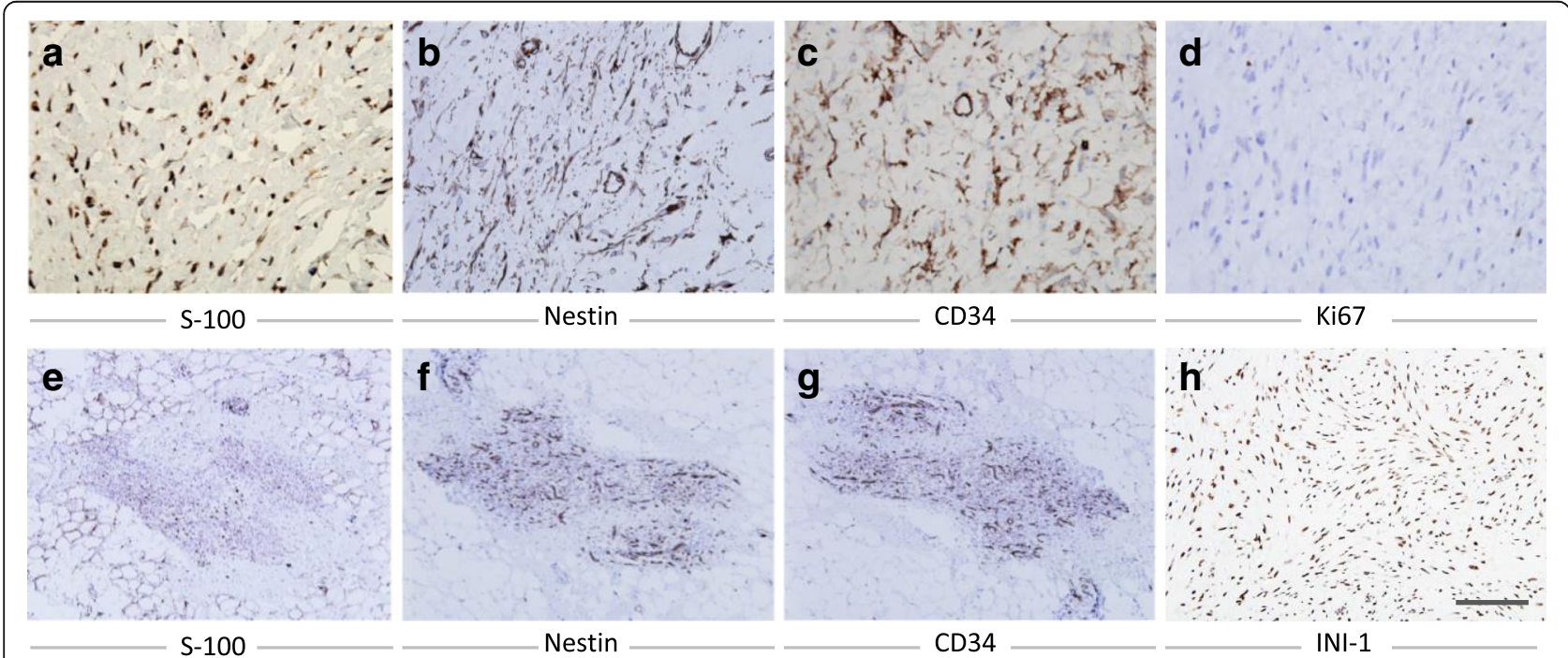

Fig. 4 Images of immunohistochemical results of ossifying fibromyxoid tumors. Lesion cells stain positive for S-100, nestin, CD34 and INI-1 (a-c, h). $2 \%$ lesion cells stain positive for Ki67 (d). Small lesions in the tissues adjacent to the tumor show positive stain for S-100, nestin and CD34 (e-g). Scale bar: $100 \mu \mathrm{m}(\mathbf{e}-\mathbf{g}), 50 \mu \mathrm{m}$ (h), $25 \mu \mathrm{m}(\mathbf{a}-\mathbf{d})$ 
almost all cases with an increased mitotic activity of $>2$ per 10 HPFs $(14 / 15,93 \%)$. Distant metastasis was a rare event that occurred in only 4 of 78 cases (5\%), and in all cases, it was associated with recurrent disease and increased mitotic activity. Two patients with distant metastasis died of the disease.

\section{Discussion}

OFMT is a rare musculoskeletal tumor of borderline malignant potential $[2,27]$. The etiopathogenesis and exact line of differentiation of OFMT is presently unclear [27]. Evidence exists for schwannian or neuronal differentiation, but this has not been well proven [12, 27-29]. Similarly, cartilaginous or myoepithelial differentiation was proposed by Enzinger et al. [1] and Kilpatrick et al. [30]. From these hypotheses, Graham et al. [27] suggested a "scrambled" phenotype for these tumors.

Since the first description by Enzinger et al. [1], several case reports and series have documented OFMT in various anatomical locations. Men are affected more frequently than women, with a wide age range of 181 years (median, 50 years) [1, 4-8, 10-26]. The head and neck region is an infrequent anatomical location for OFMT; in our literature review, we identified 87 cases, and we report 1 further case in a unique location within the submandibular gland, which was the first OFMT case in our institution. Oral lesions are even rarer and have been reported to occur in the gingiva, palatal mucosa, and tongue. A total of 8 confirmed cases of oral cavity OFMT have been published [4-7, 17, 24, 25, 31].

The clinical presentation of OFMT in the head and neck does not differ much from that in other anatomical regions. Head and neck OFMT presents as a wellcircumscribed, slow-growing, painless, and subcutaneous/submucosal mass. However, nasal cavity OFMT usually presents as pain and nasal congestion. These tumors normally have a longstanding clinical course, ranging from 1 to 20 years, or even longer (median, 4 years) [3, 32]. On radiographic examination, OFMT presents as a nodular soft tissue mass with an incomplete peripheral rim of ossification [27, 33]. CT reveals a peripheral "bone shell" in at least $60 \%$ to $70 \%$ of cases $[15,27]$. In our reported case, the lesion presented with a mixed phenotype with peripheral hard tissue composition.

OFMT histopathology is characterized by the presence of uniform lobules, round to fusiform-shaped cells arranged in nests and cords, and set in a variably fibromyxoid stroma [27]. Approximately $70 \%$ of lesions are surrounded by an incomplete shell of metaplastic (hypocellular) lamellar bone, and the other $30 \%$ lack the bone shell (non-ossifying variant) [27, 33]. Our reported case was surrounded by a shell of lamellar bone. OFMT are typically positive for S-100 and vimentin (70\%), often show desmin positivity, and can also express Leu-7, neuron-specific enolase, glial fibrillary acidic protein, and $\alpha$-SMA [27, 33]. From the immunohistochemical and ultrastructural findings, a preponderance of evidence has suggested that OFMT is of neuroectodermal origin [12, 27, 29, 30]. Vimentin and S-100 staining is often positive and can be recommended as a useful adjunct to determine the pathologic diagnosis. Genetic analyses have demonstrated that INI-1 gene (22q) is deleted in a small number cases of the OFMT, and immunohistochemiscal stainning for INI-1 was lost completely or in a mosaic pattern, however, in our case we didn't detect this staining pattern [34]. Nonetheless, an accurate histopathologic diagnosis of OFMT is essential to distinguish this tumor from its differential diagnoses, which include epithelioid nerve sheath tumors, such as epithelioid schwannoma, mixed tumors/myoepitheliomas, extraskeletal myxoid chondrosarcomas, and osteosarcomas [2, 27]. None of the cases of epithelioid schwannomas have the bone shell and cell-cell space is not uniform, as is seen in OFMT. Furthermore, epithelioid schwannomas often arise near a nerve, while this is rare in OFMT cases [35]. Mixed tumors/myoepitheliomas do not usually have surrounding bone; however, they have evident epithelial differentiation and show positive staining of epithelial markers, such as cytokeratins, which are not expressed in OFMT [36]. Extraskeletal myxoid chondrosarcomas are extremely rare in the head and neck region. They contain eosinophilic cells that are arranged in nests and cords with hemorrhage in some areas [37]. Osteosarcomas seldom grow in a lobular pattern, and have much more cytologic atypia and pleomorphism than the malignant form of OFMT [38].

Atypical and malignant OFMT have been described based on certain histopathologic criteria [2, 15, 27]. However, there are different opinions regarding the metastatic potential of the malignant subtype [1, 27]. Furthermore, three microscopic subtypes of OFMT have been previously described, namely, typical, atypical, and malignant, based on cellularity, nuclear grade, and mitotic activity. Folpe et al. [15] described three subtypes of OFMT (typical, atypical, and malignant); tumors that presented with a high grade or high cellularity and a mitotic rate of $\geq 2$ mitoses per $50 \mathrm{HPFs}$ were categorized as malignant OFMT, as such cases were found to be associated with distant metastasis. Other groups of tumors that did not present with the features of typical OFMT, but also did not meet the parameters for malignancy, were classified as atypical subtypes [15, 27]. In contrast, Miettinen et al. [2] reported tumors without increased mitotic activity that metastasized.

Recurrences have been reported in a considerable number of OFMT cases [1]. The clinical and histologic features of the recurrent tumors have not been consistently different from those of nonrecurring lesions [5]. 
An increase in cellularity and greater mitosis has been observed in some of the recurrent tumors, which is supported by our review. The incidence of recurrence of head and neck-specific OFMT has been previously described by Kondylidou-Sidira et al. [5] and we obtained the same value of $21 \%$. In our case, mitotic activity, cytologic atypia, and pleomorphism were rarely seen under the microscope; however, extracapsular growth of the tumor cells was obvious, indicating the multi-focal growth pattern. These surrounding tumor cells shared similarities in morphology and staining pattern with the cells within the tumor itself. Fat tissues were observed around the tumor which was a signature in this case and it had aroused some speculations that whether the tumor was originated from the fat tissues or not. To answer this question we need constant accumulation and observation of cases in the future. Besides, further investigation is required to determine whether this type of growth pattern is associated with a risk of recurrence. Therefore, predictors of the malignancy and recurrence of OFMT are subjects of research and discussion in the future.

Surgical management is the initial treatment of choice for head and neck OFMT. Local excision is described as the primary therapy, which is curative in most cases. However, close follow-up is recommended, especially in atypical and malignant histopathologic types, because of the previously discussed propensity for local recurrences and distant metastases. In recurrent cases, wide and more radical excisions with secure margins would be the appropriate treatment. Adjuvant radiotherapy does not seem to be indicated, except for the management of distant metastasis or unresectable disease.

\section{Conclusions}

It is hoped that a greater understanding of OFMT in the head and neck region will avoid potential misdiagnosis, and contribute to determining the correct management, which appears to be complete surgical excision with close follow-up for recurrencesurveillance.

\section{Abbreviations \\ CK: Cytokeratin; CT: Computed tomography; DOD: Died of disease; EMA: Epithelial membrane antigen; F: Female; GFAP: Glial fibrillary acidic protein; HPF: High-power field; L: Left; M: Male; mo: Months; N/D: Not described; NF: Neurofilament; OFMT: Ossifying fibromyxoid tumor of soft parts; R: Right; SMA: Smooth muscle actin; wk.: Week; y: Years}

\footnotetext{
Acknowledgements

The authors would like to thank Miss.Bai and Ms Xu, clinical technologists of the department of Oral Pathology, Peking University School and Hospital of Stomatology for performing the immunohistochemistry. We also thank Dr. Li Binbin for giving the diagnosis.
}

\section{Funding}

This study was supported by the National Nature Science Foundation of China (81702689).

\section{Availability of data and materials}

The dataset supporting the conclusions of this article is included within the article.

\section{Authors' contributions}

IAVcollected the patient's data, made the review and drafted the manuscript. RZ prepared and observed pathology specimens and also drafted part of the manuscript. DCW performed the surgery, managed the patient and collected part of the data. TJL helped to give the diagnosis and draft the manuscript. All authors have read and approved the final manuscript.

Ethics approval and consent to participate

Not applicable

\section{Consent for publication}

Written informed consent for publication of their clinical details and/or clinical images was obtained from the patient. A copy of the consent form is available for review by the Editor of this journal.

\section{Competing interests}

The authors declare that they have no competing interests.

\section{Publisher's Note}

Springer Nature remains neutral with regard to jurisdictional claims in published maps and institutional affiliations.

\section{Author details}

'Department of Oral and Maxillofacial Surgery, Peking University School and Hospital of Stomatology, 22 South Zhongguancun Avenue, Beijing 100081, People's Republic of China. ${ }^{2}$ Department of Oral Pathology, Peking University School and Hospital of Stomatology, Beijing, People's Republic of China.

Received: 25 May 2017 Accepted: 12 March 2018

Published online: 27 March 2018

\section{References}

1. Enzinger FM, Weiss SW, Liang CY. Ossifying fibromyxoid tumor of soft parts. A clinicopathological analysis of 59 cases. Am J Surg Pathol. 1989;13(10): 817-27.

2. Fletcher CDM, Unni KK, Mertens F. World Health Organization classification of Tumours. In: Pathology and genetics of Tumours of soft tissue and bone. Lyon: IARC Press; 2002. p. 196-7.

3. Schneider N, Fisher C, Thway K. Ossifying fibromyxoid tumor: morphology, genetics, and differential diagnosis. Ann Diagn Pathol. 2016;20:52-8.

4. Williams SB, Ellis GL, Meis JM, et al. Ossifying fibromyxoid tumour (of soft parts) of the head and neck: a clinicopathological and immunohistochemical study of nine cases. J Laryngol Otol. 1993;107(1):75-80.

5. Kondylidou-Sidira A, Kyrgidis A, Antoniades $\mathrm{H}$, et al. Ossifying fibromyxoid tumor of head and neck region: case report and systematic review of literature. J Oral Maxillofac Surg. 2011;69(5):1355-60.

6. Nonaka CF, Pacheco DF, Nunes RP, et al. Ossifying fibromyxoid tumor in the mandibular gingiva: case report and review of the literature. J Periodontol. 2009;80(4):687-92

7. Schofield JB, Krausz T, Stamp GW, et al. Ossifying fibromyxoid tumour of soft parts: immunohistochemical and ultrastructural analysis. Histopathology. 1993;22(2):101-12.

8. Williams RW, Case CP, Irvine GH. Ossifying fibromyxoid tumour of soft parts-a new tumour of the parotid/zygomatic arch region. Br J Oral Maxillofac Surg. 1994;32(3):174-7.

9. Ng WK. Pathologic quiz case 2. Ossifying fibromyxoid tumor. Arch Otolaryngol Head Neck Surg. 1995;121(11):1321-3.

10. Thompson J, Castillo M, Reddick RL, et al. Nasopharyngeal nonossifying variant of ossifying fibromyxoid tumor: CT and MR findings. AJNR Am J Neuroradiol. 1995;16(5):1132-4.

11. Lax SF, Ratschek M, Steindorfer P, et al. Ossifying fibromyxoid tumour of the neck clinically mimicking a primary neoplasm of the thyroid gland. Pathol Res Pract. 1995;191(1):57-60. discussion 61-3

12. Zamecnik M, Michal M, Simpson RH, et al. Ossifying fibromyxoid tumor of soft parts: a report of 17 cases with emphasis on unusual histological features. Ann Diagn Pathol. 1997;1(2):73-81. 
13. Ekfors TO, Kulju T, Aaltonen M, et al. Ossifying fibromyxoid tumour of soft parts: report of four cases including one mediastinal and one infantile. APMIS. 1998;106(12):1124-30.

14. Paschen C, Guski H, Haake K. Ossifying fibromyxoid tumor of soft parts. Laryngorhinootologie. 2001;80(9):522-4.

15. Folpe AL, Weiss SW. Ossifying fibromyxoid tumor of soft parts: a clinicopathologic study of 70 cases with emphasis on atypical and malignant variants. Am J Surg Pathol. 2003;27(4):421-31.

16. Al-Mazrou KA, Mansoor A, Payne M, et al. Ossifying fibromyxoid tumor of the ethmoid sinus in a newborn: report of a case and literature review. Int J Pediatr Otorhinolaryngol. 2004;68(2):225-30.

17. Mollaoglu N, Tokman B, Kahraman S, et al. An unusual presentation of ossifying fibromyxoid tumor of the mandible: a case report. J Clin Pediatr Dent. 2006;31(2):136-8.

18. Park DJ, Miller NR, Green WR. Ossifying fibromyxoid tumor of the orbit. Ophthal Plast Reconstr Surg. 2006;22(2):87-91.

19. Seykora JT, Kutcher C, van de Rijn M, et al. Ossifying fibromyxoid tumor of soft parts presenting as a scalp cyst. J Cutan Pathol. 2006;33(8):569-72.

20. Suehiro K, Pritzwald-Stegmann P, Lee KM, et al. Mediastinal and pulmonary metastases of malignant ossifying fibromyxoid tumor. Ann Thorac Surg. 2006;81(6):2289-91.

21. Blum A, Back W, Naim R, et al. Ossifying fibromyxoid tumor of the nasal septum. Auris Nasus Larynx. 2006;33(3):325-7.

22. Miliaras D, Meditskou S, Ketikidou M. Ossifying fibromyxoid tumor may express CD56 and CD99: a case report. Int J Surg Pathol. 2007;15(4):437-40.

23. Hirose T, Shimada S, Tani T, et al. Ossifying fibromyxoid tumor: invariable ultrastructural features and diverse immunophenotypic expression. Ultrastruct Pathol. 2007:31(3):233-9.

24. Sharif MA, Mushtaq S, Mamoon N, et al. Ossifying fibromyxoid tumor of oral cavity. J Coll Physicians Surg Pak. 2008;18(3):181-2.

25. Miettinen $M$, Finnell $V$, Fetsch JF. Ossifying fibromyxoid tumor of soft partsa clinicopathologic and immunohistochemical study of 104 cases with long-term follow-up and a critical review of the literature. Am J Surg Pathol. 2008;32(7):996-1005

26. Dantey K, Schoedel K, Yergiyev V, et al. Ossifying Fibromyxoid tumor: a study of 6 cases of atypical and malignant variants. Hum Pathol, 2017;60: 174-179.

27. Bakiratharajan D, Rekhi B. Ossifying Fibromyxoid tumor: an update. Arch Pathol Lab Med. 2016:140(4):371-5.

28. Donner LR. Ossifying fibromyxoid tumor of soft parts: evidence supporting Schwann cell origin. Hum Pathol. 1992;23(2):200-2.

29. Matsumoto K, Yamamoto T, Min W, et al. Ossifying fibromyxoid tumor of soft parts: clinicopathologic, immunohistochemical and ultrastructural study of four cases. Pathol Int. 1999:49(8):742-6.

30. Kilpatrick SE, Ward WG, Mozes M, et al. Atypical and malignant variants of ossifying fibromyxoid tumor. Clinicopathologic analysis of six cases. Am J Surg Pathol. 1995;19(9):1039-46.

31. Ohta K, Taki M, Ogawa I, et al. Malignant ossifying fibromyxoid tumor of the tongue: case report and review of the literature. Head Face Med. 2013;9:16.

32. Rubin BP, SG, World Health Organization classification of Tumours. Pathology and genetics of tumors of soft tissue and bone, ed. U.K. Fletcher CD, Mertens F. Vol. 5. 2002, Lyon: IARC Press.

33. Graham RP, Weiss SW, Sukov WR, et al. PHF1 rearrangements in ossifying fibromyxoid tumors of soft parts: a fluorescence in situ hybridization study of 41 cases with emphasis on the malignant variant. Am J Surg Pathol. 2013;37(11):1751-5.

34. Zhao D, Cai C, Zheng $Q$, et al. Vancomycin pre-treatment impairs tissue healing in experimental colitis: importance of innate lymphoid cells. Biochem Biophys Res Commun. 2017;483(1):237-44.

35. Hart J, Gardner JM, Edgar M, et al. Epithelioid Schwannomas: an analysis of 58 cases including atypical variants. Am J Surg Pathol. 2016:40(5):704-13.

36. Gao M, Hao Y, Huang MX, et al. Salivary gland tumours in a northern Chinese population: a 50-year retrospective study of 7190 cases. Int J Oral Maxillofac Surg

37. Aigner T, Oliveira AM, Nascimento AG. Extraskeletal myxoid chondrosarcomas do not show a chondrocytic phenotype. Mod Pathol. 2004;17(2):214-21.

38. Vassiliou LV, Lalabekyan B, Jay A, et al. Head and neck sarcomas: a single institute series. Oral Oncol. 2017;65:16-22.

\section{Submit your next manuscript to BioMed Central and we will help you at every step:}

- We accept pre-submission inquiries

- Our selector tool helps you to find the most relevant journal

- We provide round the clock customer support

- Convenient online submission

- Thorough peer review

- Inclusion in PubMed and all major indexing services

- Maximum visibility for your research

Submit your manuscript at www.biomedcentral.com/submit

) Biomed Central 